\title{
CARACTERIZAÇÃO DO LENHO DE FUSTE, GALHOS E RAÍZES DE ESPÉCIES UTILIZADAS NA ARBORIZAÇÃO URBANA
}

\author{
Celso Milaneto Junior*, Mariana N. dos Reis, Cinthya Bertoldo, Raquel Gonçalves
}

\section{Resumo}

Os esforços provocados nas árvores, assim como a inserção desses seres vivos em locais que prejudiquem seu bom desenvolvimento, tornam as espécies urbanas susceptíveis a queda de parte de sua estrtutura ou de sua estrutura como um todo, apresentando riscos significativos à população e aos bens urbanos. Deste modo, o conhecimento das propriedades mecânicas da madeira, na condição de umidade na qual a árvore se encontra viva, é muito importante para permitir antecipar o comportamento das árvores frente a solicitação de esforços a que estão submetidas. $O$ objetivo da pesquisa foi caracterizar parâmetros acústicos e mecânicos da madeira de galhos, de tronco e de raízes de espécies da arborização urbana; e comparar os resultados destes parâmetros nas diferentes partes que compõem a árvore. Os resultados mostraram que apenas a velocidade radial apresentou valores distintos para as raíses, galhos e tronco.

Palavras-chave: ultrassom, resistência, rigidez.

\section{Introdução}

O conhecimento das propriedades mecânicas da madeira, na condição de umidade na qual se encontra na árvore viva, é muito importante para permitir antecipar o comportamento das árvores frente à solicitação dos esforços a que estão submetidas. As avaliações de risco de queda de árvores usualmente são realizadas através de analise visual de sua sanidade e equilíbrio estrutural, inserindo certa subjetividade em um assunto tão importante. Os ensaios não destrutivos vêm ocupando cada vez mais espaço neste cenário para auxiliar e complementar estas análises.

O objetivo dessa pesquisa foi caracterizar parâmetros acústicos e mecânicos da madeira de galhos, de tronco e de raízes de espécies da arborização urbana; e comparar os resultados destes parâmetros nas diferentes partes que compõem a árvore.

\section{Resultados e Discussão}

Os ensaios de propagação de ondas foram realizados com o equipamento de ultrassom (UsLab, Agricef, Brasil) e transdutores de $45 \mathrm{kHz}$ de faces exponenciais, afim de obter velocidades longitudinais de propagação das ondas ultrassônicas na direção das fibras, na direção perpendicular à fibra e ensaios indiretos (com os transdutores posicionados a $45^{\circ}$ e na mesma face Figura 1).

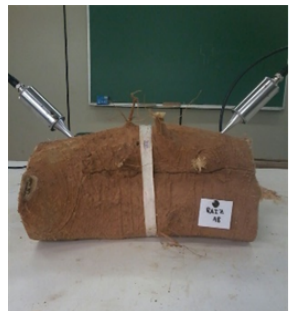

Figura 1. Ensaio de ultrassom indireto com propagação longitudinal de ondas.

Amostras das peças caracterizadas por métodos acústicos também foram ensaiadas com testes de compressão com a máquina universal de ensaios (DL 30000, EMIC, Brasil) e corpos de provas prismáticos instrumentados com strain gages (KFG-5-120-c1-11, KYOWA, Japão).

Para ambos os ensaios, as amostras de tronco foram retiradas de duas alturas (uma na altura do peito, e outra rente ao solo). As peças de raízes foram retiradas das laterais do sistema radicular, após a região do neilóide. Os galhos foram cortados no sentido longitudinal de crescimento, nas três primeiras ramificações das árvores.

Tabela 1. Valores médios das velocidades longitudinal $\left(V_{L L}\right)$, radial $\left(V_{R}\right)$ e indireta $\left(V_{\text {ind }}\right)$, coeficiente de rigidez $\left(C_{L L}\right)$, rigidez $\left(E_{c 0}\right)$ e resistência $\left(f_{c 0}\right)$ de diferentes partes da árvore (tronco, galho e raiz).

\begin{tabular}{lccc}
\hline Parâmetros & Tronco & Galho & Raiz \\
\hline $\left.\mathbf{V}_{\mathrm{LL}} \mathbf{( m . s}^{-1}\right)$ & $3683(\mathrm{a})$ & $3725(\mathrm{a})$ & $3822(\mathrm{a})$ \\
$\left.\mathbf{V}_{\mathbf{R}} \mathbf{( m . s}^{-1}\right)$ & $1367(\mathrm{a})$ & $1852(\mathrm{~b})$ & $2295(\mathrm{c})$ \\
$\mathbf{V}_{\text {ind }}\left(\mathbf{m} . \mathbf{s}^{-1}\right)$ & $3692(\mathrm{a})$ & $3672(\mathrm{a})$ & $3423(\mathrm{a})$ \\
$\mathbf{C}_{\mathrm{LL}}(\mathbf{M P a})$ & $5950(\mathrm{a})$ & $6147(\mathrm{a})$ & $6134(\mathrm{a})$ \\
$\mathbf{E}_{\mathrm{c} 0}(\mathbf{M P a})$ & 7062 & 10767 & 6134 \\
$\mathbf{f}_{\mathrm{c} 0}$ (MPa) & 29 & 25 & 23 \\
\hline
\end{tabular}

Letras diferentes nas linhas indicam valores estatisticamente diferentes.

Os resultados apresentados mostram que apenas para a velocidade radial houve diferença estatisticamente significativa nas diferentes partes da árvore. As velocidades longitudinal e indireta, assim como o coeficiente de rigidez não apresentou diferença entre tronco, galho e raiz. Não foi possível a análise estatística para os parâmetros de resistência e de rigidez devido ao número reduzido de ensaios realizados.

\section{Conclusões}

A velocidade radial apresentou valores distintos para as diferentes partes da árvore. As velocidades longitudinais e indiretas, assim como o coeficiente de Poisson foram iguais estatisticamente para a madeira proveniente do tronco, do galho e da raiz da árvore.

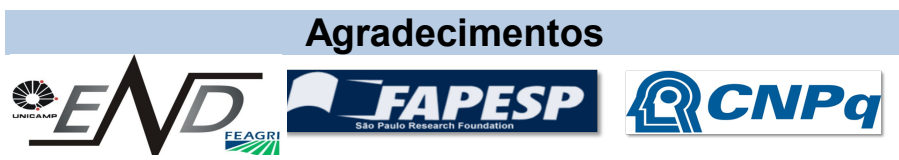

